\title{
Mental Tests of Dementia*
}

\author{
A Consideration of Various Doctrines and Results of Some Investigations
}

\section{By Bernard Hart, M.D., University College Hospital, London, and C. Spearman, Ph.D., University of London}

"Mental Tests" signify any mental performances whatever used for diagnosis, provided that they are standardized, that is, arranged so as to admit of repetition by other experimenters or subjects.

Among persons unfamiliar with scientific psychology, there is a tendency to depreciate such tests on account of their usual lack of serious motive. How, it is asked, can the depths of human intelligence be sounded by can the depths of human intelligence be sounded by
tasks of obvious triviality? But this is a confusion tasks of obvious triviality? But this is a confusion
between the intellectual task itself and its accompanibetween the intellectual task itself and its accompani-
ment of emotion, conation, valuation, etc. The two are so distinct, that a task which to-day seems trivial may. to-morrow be clad with intense interest. To render intellectual tests emotional would be a superfluous and, indeed, highly disturbing complication.

A more formidable objection to them is their unsuccessful past. They were given a friendly welcome and careful application by some psychiatrists of first rank, careful application by some psychiatrists of first rank,
who had to admit that their expectations were woefully who had to admis
disappointed.

disappointed.
'This at once brings us to the heart of the present problem. For these investigators, in common with most psychiatrists and psychologists, seem still to retain an essential portion of the old doctrine of "faculties"; they regard mental activity as made up of elements such as "observation," "discrimination," "association," "memory," etc. True enough, they discard the former metaphysical implications and scrupulously replace the discredited word "faculty" by the more modern term, "process"; but they still incline to the generalization implied in the older word, and take their "observation," "implied in the older word, and take their "observation," tacitly assume, for instąnce, that when a person has shown low power of "observing" one class of objects, he will be similiarly inefficient in observing other classes. $^{2}$ But when their assumption is thus stated explicitly, it becomes at least questionable.

Even those who stop short of such trenchant generalizations are liable to the same tendency in milder eralizations are liable to the same tendency in milder
degree. One experimenter, for example, found that the senile dements examined by him could recognize only a senile dements examined by him could recognize only a
comparatively small number of words exposed momencomparatively small number of words exposed momenthe general conclusion that such dementia is specially characterized by smallness of field of consciousness Another writer, on the evidence of one test of the hebephrenic dements under his care, asserts their fundamental defect to lie in their faulty formation of concepts. While a further investigator of the same class of patients concludes on similarly narrow evidence that of patients concludes on similarly narrow evidence that
their real weakness resides in the action of the "overidea" directing their thoughts. In short, psychiatryidea" directing their thoughts. In short, psychiatry-
and indeed, almost all current individual psychologysoars lightly to sweeping generalizations, which the slow steps of science could only hope to obtain by arduous research

Recently, a few psychologists have made a protest. They have realized that to bring two mental performances under such a category as "observation," etc., is merely to find that they resemble one another in the particular aspect denoted by the word "observe"; this aspect is not necessarily more dominant than the countaspect is not necessarily more dominant than the count-
less other ones in which the two performances may less other ones in which the two performances may
differ. But this school, not content with discarding the obviously unwarranted assumptions of functional unity, has gone on to deny functional unity of any kind, an to declare that a person's capacities for completely different performances are entirely independent of one another. Hereby, they have laid themselves open to the reproach of "throwing out the child with the bath,"
and of reaching a position as clearly opposed to fact as and of reaching

It has been left, then, for a third school to pick out and supplement the part truth contained in both the older views. As usual, matters have turned out to be less simple than appeared to any of the earlier theorizers. A very large mass of evidence has been brought to show that a person's success in any intellectual perfactors."

The one is "specific ability" for the performance in question with all its particular features. Suppose, for

* Abstract from a paper published in The Journal of Abnorma Psychology.

ISee, for instance, Kraepelin and Cron, Psych. Arbeiten, II
p. 324.

2 Whether this inefflciency takes the form of weakened, exce
sive, or ataxic function, is immaterial for our present purpose Brit. J. Psychology, V, 1912, p. 51. instance, that a schoolboy has surpassed his fellows in the observation of birds' nests. His victory has, no doubt, depended in part on his capacity for the general form of mental activity known as "observation." But it has also depended on his being able to apply this form of activity to the matter of birds' nests; had the question been of tarts in the pastry cook's window, the laurels might well have fallen to another boy. A further influence must have been exercised by the accompanying circumstances; to spy out nests as they lie concealed in foliage is not the same thing as to make
observations concerning them in the open light of a observations concerning them in the open light of a
natural history museum. Again, to discover nests at leisure is different from doing so under the severe speed limits prescribed by the risk of an interrupting gamekeeper. The boy's rank may even depend largely on the manfer of estimating merit; marks may be given either for the gross number or for the rarity of the nests observed; and he who most infallibly notes the obvious construction of the house-sparrow may not be obvious construction of the house-sparrow may not be
the best at detecting the elusive hole of the kingfisher. Every one of these features of the observation, thenand their number might be indefinitely extended-must be considered as capable of influencing the success of our hypothetical boy; one and all constitute elements of the "specific ability" concerned. Any performance may have a large or small proportion of such elements in specific ability for the one may have much or little overlapping with that for the other. Clearly, when the overlapping is so great that the two performances are almost identical, a person's success in one of them must give probability of success in the other also, and the two performances must become highly correlated with one another. Investigation has proved, however, that when two performances have not any such large overlapping, but have in common only the general form of activity as expressed in such words as "observation," appreciable correlation between the two specific abilities; the latter remain independent of one another.

But overwhelming evidence had recently been brought of the existence of a second factor, whose nature is essentially different. To the extent that this is operative, all intellection whatever forms one single functional unit, power in any one performance going perfectly parallel with power in every other performance, however much they may differ in general form of activity or otherwise. Owing to this factor, any kind of memory, for instance, may show itself to correlate with discrimination, association, conception, etc., as much as, or even more than, with a different kind of memory.
This second factor has accordingly been termed by us "general ability."

Thus, while the range of the specific factor is exceedingly narrow, that of the general factor is universal and between these two there appears to be no intermediate. There are plenty of words, indeed, whose range is of an intermediate character, such as the above fretion," etc.; each of these denotes a very large group of activities, yet falls far short of embracing all intellecactivities, yet falls far short of embracing all intellec-
tion. For many purposes such groupment is serviceable tion. For many purposes such groupment is serviceable
enough. But when considering functional unity, these words only give rise to extremely mischievous and pertinacious illusions."

The theory of "two factors" just delineated, though primarily of psychological origin, has shown itself capable of translation into terms of cerebral physiology and thereby it seems to gain in clearness and sug with the efficiency of the particular cortical region, or with the efficiency of the particular cortical region, or
other neural characteristic, ular performance in question; so far, we do not transcend the ordinary accepted localization of cerebra function. But the general factor is taken as corre sponding to the efficiency of the entire cortex, or som still more extensive neural area; and this is a propo sition evidently requiring some justification. -It is not; however, intended to assert that these two factors,
specific and general, exhaustively sum up a person's whole intellectual make-up.

- In the rest of this paper, to save repetition, we shall simply a particular cortical region. But really, this is only one out of the
many conceivable particular neural characteristics which may be
the substratum of a particular intellectual performance. Pending the decision of physiology on this point, we have chosen cort cal regions as certainly applying in some cases (e.g., aphasia)
and as being the most readily intelligible. Possibly, some of these and as being the most readily intelligible. Possibly, so
speciflc factors may turn out to be Mendelian units.
One good reason for this general factor can be furnished without difficulty; this is the fact that various influences affect the whole cortex in common. The chief are its derivation from the same original pair of germ cells, and its nourishment by the same general blood supply. Such conditions common to the whole cortex must tend to produce a common level of excellence in the function of each of its parts; for when the conditions are favorable to one part, they will probably be so more or less to others also. It is on very analogous grounds that the hair of one region of a person's scalp usually resembles that on other regions.

But there is a further reason, one frankly hypothetical, yet perhaps of still greater importance. A number of psychic phenomena-association, fatigue, and above all, "the narrowness of consciousness"-cogently indicate that each momentary focus of cortical activity receives continual support from energy liberated

Thus far we have given an outline of the "theory of two factors," as it has been developed in normal psychology, and alone appears consonant with the facts elicited by exact investigation of the normal psychic processes. Let us now briefly consider the bearings of this theory on pathology. Take, first, the effect of the fact of the entire cortex having sprung from the same germ cell. Hereby, a tendency must arise for excellence in one part to be accompanied by excellence in other parts, just as in agriculture any soils of common geological origin will be apt to resemble one another in degree of fertility. But such an original correlation degree of fertility. But such an original correlation
between different parts cannot be expected to extend to their subsequent fates; a "static" correlation does not produce a "dynamic" one; neglecting to manure one field will not abolish the fertility of others belonging to the same geological stratum. And in the same way, damage to one region of the cortex- whether by infiltration of blood, by toxin or abscess-will not necessarily extend to other regions.

Take, next the correlation engendered by the different parts of the cortex all depending on the same blood supply. This has, indeed, a "dynamic" character; damage in any cortical region by toxic or insufficiently oxygenated blood will tend to be accompanied by corre sponding damage in other regions also. But physiological experience has shown that this inferiority of the blood supply affects the different regious very unequally; usually, in a few places the neurons will be found to suffer from granular degeneration, opaque nucleus, scanty tangential fibers, etc., while everywhere else the changes, if any, will be so minute as to escape scrutiny. Consequently, as far as this influence of the blood is concerned, we should expect any intellectual impairment to show a patchy character, being severe for a few kinds of performances, but having little or no effect on the great majority of kinds. Moreover, this "dynamic" correlation, such as it is, will be limited to maladies arising from intoxication or other diffuse causes. Wherever the cortical injury appears on macroscopic and microscopic examination to be narrowly localized, there we must expect similarily isolated mental injury; otherwise we have to introduce a deus ex machina in the shape of extremely hypothetical lesions, so slight as to escape all present means of detection, yet so complete as permanently to destroy function.

All this becomes quite changed, however, if we admit that the activity of any cortical region requires continual support from energy derived from the entire cortex. To some extent, indeed, the mental injury must still continue to run parallel to the lesion; any mental performances directly or indirectly subserved by this particular region must show a precisely corresponding specific disturbance. But over and above this, there must invariably be found a mental impairment far must invariably be found a mental impairment far to all intellectual performances whatever. As regards the quality of this general impairment, it should be independent of the seat of the physiological lesion and of the nature of the malady. As regards its intensity it should most affect just those performances which are - For this psychological evidence, we must refer to our previous
paper, Brit. J. Psych., v, 1912, p. 67. Nor does the present paper, Brit. J. Psych., V, 1912, p. 67. Nor does the present
place appear suitable for discussing the probable mechansim of place appear suitable for discussing the probable mechansim of
the supporting action of the entire cortex. It may be mentioned however, that the belief in such a support has shown itself com-
patible with very divergent neurological views; it has been compatible with very divergent neurological views; it has been com-
bined with the drainage theory by McDougall ("The Physiological
Factors of the Attention-Process," Mind, XI, N. S., 1902), with Verworn's theory of interference by Lehmann ("Grundzlige der Psychophysiologie," 1912, p. 194), and with neo-vitallsm by
Walsh ("PBychotheraphy, "1912, p., 133). 
shown in the case of normal persons to depend in the highest degree on the "general ability."

In selecting our tests, we aimed principally at obtaining samples from very varied regions of mental activity, so that any general results obtained might have the widest possible range of validity. For this purpose, we took one case of sensory perception, one of quick and took one case of sensory perception, one of quick and accurate usage of well-worn associative paths, on
where the activity was of a more elaborately synthetic character, and one depending on wealth and discrimination of ideas.

But, at the same time, we desired also to learn something about the behavior of tests more closely resembling one another. We took, therefore, two tests of memorizing exactly similar except in one single point, and another test of memorizing differing from both in three points only. Also, we arranged three motor tests, three points only. Also, we arranged three motor tests,
one depending in the most simple manner on speed of successive innervations, another involving also some appreciable degree of perceptual activity, and a third requiring delicacy of co-ordination.

COMPARISON OF TESTS MADE WITH ESTIMATES OF INTELLIGENCE.

Our interpretation of experimental results seems to lead to a paradox. The saturation co-efficient of these estimates, giving the degree in which the estimates truly represent the intelligence, amounts only to 0.55 instead of nearly unity, as might have been expected. If we make a direct comparison of the ranks assigned to the patients by the estimates with those assigned by all the tests pooled, the result is still the same, the correlation being only 0.57 . The results for the sane subjects are, as far as they go, in a similar direction. All seems to Indicate that the estimates form a less reliable guide as to the patient's real intelligence than do several of the experimental tests. This goes even beyond the results of previous investigators. In the beyond the results of previous investigators. In the
work of Abelson, for instance, such estimates were inwork of Abelson, for instance, such estimates were in-
deed found greatly inferior to the pool of several tests together, but they were distinctly better than any single test taken alone. ${ }^{8}$ Burt came to the same conclusion.

To get at the root of this discrepancy between the estimates and the tests, we may begin by considering the sources of error from a very broad point of view. We can scarcely do better than avail ourselves of the masterly words of Bacon: "The mind, darkened by it covering the body, is far from being a flat, equal, and clear mirror that receives and reflects the rays without mixture, but rather a magical glass, full of superstitions and apparitions. Idols are imposed upon the understanding, either (1) by the general nature of mankind; (2) the nature of each particular man; or (3) by words, or communicative nature. The first kind we call idols of the tribe; the second kind, idols of the den and the third kind, idols of the market."

From the first kind, or idols of the tribe, the tests have never been proved to suffer. Whereas estimates, even when apparently quite independent, have recently been shown experimentally to be influenced by such idols to a remarkable degree.

The second kind, or idols of the den, obviously affect any single test largely; they vitiate it to just the exten that it depends on the particular cortical region involved as opposed to the whole cortex; but their perverting influence diminishes in proportion to the number of tests pooled together. It is wrong, however, to imagine that these idols do not affect the estimates also. Their influence here admits of exact determination, being repinfluence here admits of exact determination, being rep-
resented by the correlation between the estimates of resented by the correlation between the estimates of
different judges of the same persons; this proves in our different judges of the same persons; $t$
investigation to be no more than 0.66 .

investigation to be no more than 0.66 .
Lastly, from the idols of the market place the test are clearly exempt. But as regards the estimates, on must agree with Bacon that these idols "give the gravest disturbance." And they are bound to be peculiarly where the constant inter-communication, and the mutual suggestion, between the members of the asylum staff must inevitably engender a more or less uniform "plane" of general opinion. On the whole, then, these a priori consideration are far from confirming the a priori consideration are far from confirming the
popular tendency to value the tests strictly according to their agreement with the estimates, but rather raise a suspicion that the latter may be the less trustworthy of the two.

Luckily, we are not confined to these a priori considerations for explaining the discrepancy between the tests and estimates. Direct light can be obtained by individual scrutiny of the most pronounced actual in
stances. First, we may pick out the patients who have

${ }^{7} A$ discussion of the probable reason for some performance depending more than others on
Prit. J. Psych., v., 1912, p. 69 .

8 Brit. J. Psych., IV. 1911, 305.
- Brit. J. Psych., III, 1909, p. 159.

See Marbe on "The Uniformity of Psychical Occurrence.

Kongress fur Exp. Psychologie, IV, 1912. been rated much lower by the estimates than by the tests; four of them stand out conspicuously from the rest. Every one of them proves to be a case of dementia præcox; this is the very malady where the estimates are subject to a grave under-estimation of ability. Then take the patients who, inversely, have been ranked much lower by the tests than by the estimates; we find only two conspicuous instances; and both are general paralysis, the disease of all others whose ravages are known to go often far deeper than outward appearances would suggest.

But over and above these sources of downright error, the discrepancy between the tests and the estimates may well derive in large part from some real difference in the objects aimed at by them. The tests claim to measure the energy of the whole cortex, a theoretical and purely quantitative matter. But the estimates of and purely quantitative matter. But the estimates of
"intelligence" can scarcely help having some degree of practical bias; they are likely to measure not so much bare quantity as efficiency, not so much clever as valid thinking. And every psychologist knows that errors of thought arise, not only from stupidity, but even more so from perverted emotion and volition.1

METHODS OF MEASURING INTELLECT.

The simplest way is to form an estimate on the basis of natural intercourse, either making some definite observations, or trusting to one's general impression. This has many disadvantages. In particular, the ordinary course of events may not happen to put the person's intellect to any unequivocal trial.

Consequently, the necessity has everywhere been felt of artificially modifying the course of events, so as to bring the person's intellectual power to more distinct expression. The usual procedure has three steps $:$ he is submitted to some sort of examination or test judged by "common sense" as likely to reveal any impairment of "intelligence"; his degree of success is estimated in the light of general experience; and on the basis of on or two such trials, the verdict is formed.

But none of these steps find much support in our ex perimental results. Our records reveal that "common sense" is but a lame guide as to what tests will exhibit the clearest evidence of mental deterioration. No one for instance, would have prophesied that of two closely
similar tests, one would exhibit nearly the greatest, and the other nearly the least depreciation of ability in insanity.

Further, psychologists are beginning to discover that the conception of "intelligence" is confused and inadequate. For our present purpose it requires replacing by two clear conceptions, each needing quite different kind of test. First, there is the "general ability," equivalent physiologically to the energy of the entire cortex. To estimate this, tests have to be devised in which the influence of the entire cortex plays as large a rôle as possible; and this influence admits of precise measure ment by means of our coefficients of "intellective saturation." But since even with the highest obtainable coefficient the influence of general ability never comcoefficient the influence of general ability never com-
pletely ousts that of specific ability, it is indispensable pletely ousts that of specific ability, it is indispensable
to take the pool of several tests. The bigger the pool, to take the pool of several tests. The bigger the pool,
the less will be the relative influence of the specific abilities, and the more clearly visible will be any impairment of the general ability.

But to determine the general ability is not sufficient. In order to diagnose the nature of the malady, we need also to find out the specific mental damage. And in this matter, there appears to be even greater urgency for further investigation. The views now current are not founded upon solid evidence.

The possession of the best tests, however, would be of little use until we knew how to value the patient's success at them. The general impression formed by the experimenter in the light of ordinary experience has been found by us to be treacherous. Our patients re peatedly exhibited errors, incapacities, and other intellectual shortcomings which, at first sight, suggested advanced dementia; but later on, we found just the same to occur with persons of blameless sanity. On the other hand, a patient's performance sometimes seemed remarkably good, until quantitative comparison with remarkably good, until quantitative comparison with
the sane showed it really to be poor. An indispensable the sane showed it really to be poor. An indispensable
requisite, then, to the evaluation of all such tests is a requisite, then, to the evaluation of all such tests is a
full record of similar performances by many normal persons. The not unusual practice of testing for com parison one single normal person appears more likely to mislead than help (Bechterew, Traité Intern., p. 149).

The value of the tests will be greatly enhanced when all psychiatrists have been induced to accept the same ones. The results gained by different experimenters, or
in different asylums, or at different dates, will then in different asylums, or at different dates, will then
become comparable with one another. The importance become comparable with one another. The importance of this unification has been urged in a most convincing
way by Sommer. But its speedy adoption can scarcely be hoped for. None of the prevalent methods of testing 11 Much light on this matter will be furnished by an investigaof us. appear to merit unanimous adoption so much as unanimous rejection.

There is a further and more serious obstacle to obtaining full value from tests, namely, the lack of reliable information concerning the patient's powers previously in health. The pathological impairment has been proved above to be quite similar in nature to the inequalities existing even among normal persons. Hence, we cannot measure how much an intellect has been af fected by malady unless we know how great it was in health. It has been suggested that only such tests should be used which all normal persons without ex ception can execute (Ziehen). But this would limit consideration of dementia to the grossest, least interesting cases. The difficulty applies in especial degree to specific abilities; for these differ so widely in health, that even the most extreme incapacity furnishes uncertain evidence of pathological deterioration.

It remains expressly to disclaim exceptional virtue for the tests employed in the present investigation. They were chosen, not as models of excellence for practical use, but as the most likely to illumine the matte and thus prepare the way for making excellent ones in the future. The chief requirements turn out to be: convenience of application, adequate reliability coefficients, and high coefficients of intellective saturation. Now, all our present tests are fairly convenient; most of them ones with tolerable coefficients of general ability are ones with tolerable coefficients of general ability are quality and quantity of sentences, accuracy and speed
of figures, accuracy and speed of addition, and perhaps speed of crossing-out rings.

An abundance of other tests will be found in the re oent literature (especially in Whipple's "Manual of Mental and Physical Tests"). It is required to make convenient selections and modifications, and then to determine their coefficients of reliability and of intelpossible to pick out really good tests of general ability.

$$
\text { FURTHER ASPECTS OF THE INTELLECT. }
$$

The facts discussed in the present paper have been found to be incompatible with the usually assumed functional unities, which are simply the old "faculties" masquerading under new names; they can only be explaine by the theory of general and specific abilities. But thi by no means implies that these two factors constitute a individuals.

To begin with, all the test performances are what may be called maximal; they show what the subjects can do under such a strong stimulus as the experimenter's exhortation to try their hardest. But it cannot be expected that such strenuous efforts should have a course closely similar to that of ordinary life. For instance, although the specific correlation between the powers of speed in different performances has been found to approximat to zero, this need not necessarily be at all the case as regards preferences of rate; on the contrary, the person who likes to do one thing in a deliberate manner is ver likely to prefer deliberateness in other things also.

Then again, our tests were of such short duration as practically to eliminate the influence of fatigue, though this under other circumstances may be very powerful. It has, indeed, been shown recently by Flügel that fatigue, like ability, is either of the whole cortex or else of some very particular cortical region $;^{12}$ but ther is no ground for assuming that the person with greatest momentary supply of cortical energy will also possess the most enduring supply.

Also, many further factors have been stated to characterize the intellection of individuals, such as "preservation," "span of consciousness," etc. The great majority of these statements are merely guesses or illicit generalizations; but a few of them are probably true and very important.

Furthermore, it will be noted that our cases are far from exhausting the whole field of mental diseases. Th classification of insanity at the present day is so unsettled, and the specific mental diseases generally
recognized are so ill-defined, that we have felt it to be unprofitable to attempt refinements of diagnosis. Only well-marked instances of commonly accepted clinical diseases have been selected for the purpose of the tests, and even with regard to these it must be clearly understood that the few comments we have ventured to make as to distinctions existing between various diseases have only a very limited and provisional value.

Finally, these tests have been arranged so as to be confined to purely intellectual factors. But in ordinary life, this simplicity is of rare occurrence; for the most we feel and want 13

CHIEF CONCLUSIONS.

1. Our experimental results appear incompatible with

12 Brit. J. Psych., VI, 1913, p. 60.

"13 A good illustration is furnished by W. McDonald in his June, 1906, p. 248. 
the current viet that dèmentia consists in large "defects," "gaps," "hyperfunctions" or "ataxias" in menta power, such as "disturbed association," "faulty judg ment," "weak power of conception," "poverty of ideas," "loss of memory," etc. For the inequality between the powers of the same person for different kinds of performance does not appear to be appreciably greater in insanity than in health, nor in one of the forms of ininsanity than in health, nor in one of the forms of in-
sanity tested than in another. Thus, in the main, the mental injury appears to be of a perfectly diffuse character or to constitute a lowering of the whole intellectual level. The fallacy of "defects" would seem to derive from taking as effects of the malady what are really perfectly normal differences between a person's powers for different performances. These misapprehended weaknesses have, further, been unduly generalized; a poor ability in some particular operation involving memory has been illegitimately taken as inefficiency ing memory has been

2. Over and above this general impairment, elaborate methods can also detect certain damages characteristic of particular maladies. These are very narrow and specific in kind, but probably may be correspondingly grave in intensity.

3. The sole theory capable of accounting for these and other results appears to be that already reached in the experimental investigation of normal persons. Acthe experto this ins. Acon two physiological factors : the particular region or on two physiological factors: the particular region or
characteristic of the cortex which is the direct substracharacteristic of the cortex which is the direct substra-
tum of that performance; and secondly, a reinforcetum of that performance; and secondly, a reinforcement or other support derived from the entire cortex.
It is the latter factor whose impairment produces all of It is the latter factor whose impairment produces all of the more readily observable signs of dementia. The inmost difficult to detect, just as is known to be the anatomical factor itself. It is very unlikely to be manifested on any mere casual examination. These specific mental injuries offer a large field urgently needing exact investigation.

4. This correspondence between the normal and pathological results has been found susceptible of an extremely crucial verification. Among normal subjects, the degree of dependence of any intellectual performance on the efficiency of the entire cortex as opposed to the specific substratum can be brought to quantitative measurement (in the coefficient of "intellective saturation"). The value obtained proves to be strictly proportional to the degree that the performance is depreportional to the
ciated in insanity.

5. The importance of this theory of two factors in ability may be exemplified by the strife of centuries concerning cerebral localization. The one school, as exemplified by Munk, has its eyes on the specific factor alone; while the other, with Goltz, has persistently had in view the general factor. The possibility is now dawning of a scientific reconciliation, in the shape of a quantitative estimate of both factors.

6. As regards practical diagnosis, the method of mental tests appears to be already capable of accurately determining any person's general level of intellectual determining any person's general level of intellectual
power. But before accurately measuring the impairpower. But before accurately measuring the impair-
ment (especially in slight cases) we require to know ment (especially in slight cases) we require to know
how great this power was in health. The determination of the specific depreciation characterizing particular maladies remains almost wholly a matter for future investigation.

7. In addition to general and specific ability, there probably remain further highly important constituents of individual intellectual make-up.

\section{The Use of Aluminium in War*}

A London newspaper recently reported the seizure, by the Norwegian authorities, of 170 tons of aluminium, which had been shipped indirectly to Germany from a neutral country. Hundreds of tons of aluminium have entered Germany from Switzerland and by way of Barcelona and Genoa, and the German submarines in the North Sea take good care not to sink vessels laden with aluminium or with copper.

Germany is in need of aluminium, and the recent rise in the price of the metal is significant. At the beginning of this year aluminium sold for about $\$ 400$ a ton. This price was fixed by the international syndicate, which was founded in 1908, when the French producers rejected the old agreement which assured the ducers rejected the old agreement which assured the
domination of the German-Swiss works at Neuhausen. domination of the German-Swiss works at Neuhausen.
In June the price of aluminium had risen to $\$ 700$ a ton. This increase does not appear to be due to any increased demand by the Allies, who use little aluminium for those military purposes which are now most urgent and important. The French producers, who are bound by their contracts, derive no benefit from the increase, which goes to enrich intermediaries, who load the price with problematical risks.

*Abstract of Nicolas Flamel's article in La Nature, July 31st,
1914. Translated for the ScIENTIFIc AMERICAN SoPpLEMENT.
Pure aluminium does not seem to merit attention for its mechanical properties. It is very soft and weak, and apparently too light to be employed in artillery. In France, where the aluminium industry was founded by the researches of Sainte-Claire Deville, the metal has been tried as a material for cartridges, shells, fuses, and camp and kit utensils. It was rejected by the artillery service and has not yet been adopted by the commissariat.

In Germany and Austria, on the contrary, aluminium has been employed and accumulated in enormous quantities, in preparation for war, and the rapid increase in the world's production of aluminium is due chiefly to this fact.

\begin{tabular}{|c|c|c|c|}
\hline $\begin{array}{l}\text { Year. } \\
1900\end{array}$ & $\ldots \ldots \ldots \quad \begin{array}{r}\text { Tons. } \\
\mathbf{7 , 3 0 0}\end{array}$ & $\begin{array}{l}\text { Year. } \\
1907\end{array}$ & $\ldots \ldots \ldots . \quad \begin{array}{r}\text { Tons } \\
\text { Tons }\end{array}$ \\
\hline 1901 & $\begin{array}{ll}\ldots \ldots \ldots \ldots & \mathbf{7 , 5 0 0}\end{array}$ & 1908 & 19,66 \\
\hline 1902 & .......... & 1909 & \\
\hline 1903 & 8,200 & 1910 & \\
\hline 1904 & $\begin{array}{ll}\ldots \ldots, 300 & 9, \ldots\end{array}$ & 1911 & 8 \\
\hline 05 & ... 11,500 & 1912 & \\
\hline & . 14,500 & 1913 & \\
\hline
\end{tabular}

The increase of 4,000 tons betwe be attrise of the automobile in dustry, but the increase continued after the check year of the Algeciras conference, and a sudden increase of 20,000 tons in a single year followed the Agadir affair in 1909 .

F'or a number of years the Germans and Austrians have used aluminium in the construction of the fuses of their shells, the canteens, pots and cups of their soldiers, and the frames of their Zeppelins. Some of the fuses are made entirely of aluminium, others are composed of aluminium and brass. Assuming that each fuse contains $\mathbf{4 0 0}$ grammes of aluminium and that 15, 000,000 fuses-a very moderate estimate-were constructed in advance, the aluminium stored up in the form of fuses would amount to 7,000 tons, which, owing to the unavoidable waste in working, represent nearly 8,000 tons of aluminium bars. It would be prudent to accumulate twice this quantity, in addition, in order to replenish the stock of fuses, and we may be sure that this precaution was taken by the methodical and provident Germans who employ a metal of so recent introduction, although they possess neither its ore (bauxite) nor abumant water power for its production. These considerations indicate a consumption of 24,000 tons of aluminium for the artillery service alone.

The soldier's individual pot, cup and canteen would require $\mathbf{7 0 0}$ grammes of aluminium, so that the equipment of five million men would require 3,500 tons, representing nearly 4,000 tons of aluminium in bars.

Each Zeppelin contains from 6.5 to 9 tons of aluminum and thirty Zeppelins are known to have been constructed, so that at least 250 tons of aluminium have been used in this way. It is impossible to estimate the quantity reserved for the construction of new Zeppelins and the equipment of fresh troops.

A few months before war was declared the German war ministry was experimenting with aluminium alloyed with 3 per cent of copper and 1 per cent of magnesium. This alloy, called duralumin, which is four times stronger and 30 per cent more extensible than pure aluminium, was used experimentally as a material for shells and cartridges. A little later it was proposed to adopt an ingenious infantry shield, made in Austria. The shield was composed of a plate of hard steel backed by a plate of duralumin. The two plates were riveted together and either of them could be covered with canvas. The shield could be carried on the left fore-arm by means of two straps. Such a shield would be lighter than the sand-bag used by French soldiers, and it could be managed with one arm, leaving both hands free. The hard steel face and soft back would give it the peculiar efficiency of a plate of Harveyized steel. - For the same reason, duralumin would have been an excelent material for helmets.

Without regarding these experiments or the ordinary uses of aluminium we reach a minimum consumption of 30,000 tons.

The Germans have also contemplated the substitution of aluminium for copper, of which they are greatly in need, despite diligent working of the Mansfeld mines, the pillage of Belgium and the capture of the French opper district of Dinanderie, and the seizure of Germa stocks of copper destined for other uses.

German shells ringed with aluminium have been found. Pure aluminium, which is softer than copper, would fill the rifling grooves and foul the guns. The filling of the grooves might be prevented by hardening the metal and guns fouled by aluminium could easily be cleaned with hot solution of caustic soda, whereas copcleaned with hot solution of caustic soda, whereas copper ca

The Germans are endeavoring to secure aluminium in every possible way. Toward the end of last year Prof. Otto N. Witt stated, in the Chemiker Zeitung, that the aluminium industry chiefly used French bauxite and that it would be necessary to turn to a similar ore, found in Dalmatia. He suggested the idea of obtaining aluminium nitrate and alumina from kaolin by the Ottokar Serpek process. The ammonia disengaged in the conversion of the nitrate into alumina could be fixed in the form of ammonium sulphate and used as a fertilizer. It would then be possible to requisition all the agricultural stocks of Chile nitrate. Aluminium, alumina, even bauxite, have been smuggled into Germany, either for new military uses or to feed the electric furnaces, whose number and output may have been increased, despite the lack of water power, by utilizing electric power derived from the coal made available by importation from conquered fields and by the diminution of German exports.

\section{SCIENTIFIC AMERICAN SUPPLEMENT \\ Founded 1876}

NEW YORK, SATURDAY, SEPTEMBER 25th, 1915

Published weekly by Munn \& Company, Incorporated

Charles Allen Munn, President; Frederick Converse Beach, Secretary; Orson D. Munn, Treasurer ;

Entered at Post Office of New York, N. Y., as Second Class Matter
Copyright 1915 by Munn \& Co., Inc.

The Scientific American Publication

Scientific American Supplement (established 1876) per year $\mathbf{\$ 5 . 0 0}$ Scientific American (established 1845) $\ldots \ldots$ “ 3.00

The combined subscription rates and rates to foreign countries,

Including Canada, will be furnished upon application
emit by postal or express money order, bank draft or chec

Munn \& Co., Inc., 233 Broadway, New York

The purpose of the Supplement is to publish the more important announcements of distinguished technologists, to digest significant articles that appear in European publications, and in science and industry throughout the world.

Back Numbers of the Scientific American Supplement

SUPPLEMENTS bearing a date earlier than January 3rd, 1914, can be supplied by the $\mathrm{H}$. W. Wilson Company, 39 Mamaroneck Avenue, White Plains, N. Y. Please order such back numbers from the Wilson Company. Supplements for January 3rd, 1914, and subsequent issues can be supplied at 10 cents each by Munn \& Co., Inc., 233 Broadway, New York.

$W_{E}$ wish to call attention to the fact that we are in a position to render competent services in every branch of patent or trade-mark work. Our staff is composed of mechanical, electrical and chemical experts, thoroughly trained to prepare and prosecute all patent applications, irrespective of the complex nature of the subject matter involved, or of the specialized, technical, ol scientific knowledge required therefor.

We also have associates throughout the world, who assist in the prosecution of patent and trade-mark applications filed in all countries foreign to the United states.

Munn \& Co., Patent Solicitor 233 Broadway, New York, N. Y.

Branch Office:

625 F Street, N. W.,

Washington, D. C.

\section{Table of Contents}

Geographic Aspects of the War.-I.-By Prof. Douglas

Wilson Johnson.-1 illustration............... 194 (100 When to Clean Turbine Blades....................... 196
How a Top Stands Up.-By J. Swinburne.-1 illustration. 197 Nickel-plating on Aluminium.................. 197 tasy and Mountain Building.-By Luigi de Marchi.1 illustration mitation Precious Stones...

Drilling for Oll......................... 199

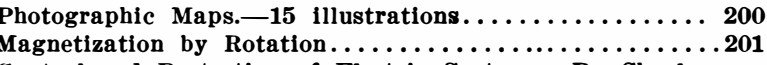
control and Protection of Electric Systems.-By Charles

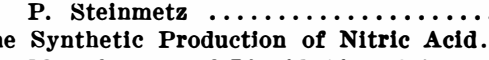

The Manufacture of Liguid Air.

The Movements of the Moon ............ 204 Mental Tests of Dementia.- - By Bernard Hart and c.

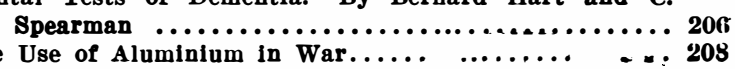

